\title{
O efêmero e nossas idolatrias pós-modernas
}

Ana Maria Tepedino

\section{Resumo}

A finalidade da pesquisa é fazer uma reflexão sobre a criação dos ídolos pós modernos para buscar perceber como estas figuras estão influenciando a identidade do país, mudando o comportamento das pessoas, sobretudo, dos jovens. A pós-modernidade realiza uma mudança de valores, aproveitada pela mídia, que tem um papel fundamental na construção destes ídolos, para poder vender os produtos que anuncia. O texto aborda várias fases: preparação, sucesso e desilusão dos ídolos.

Palavras-chave: Pós-Modernidade, Religião, Idolatria, Ética, Estética, Responsabilidade Social.

\begin{abstract}
The purpose of this research is to make a reflection about the creation of the post modern idols in order to search their influence in the country's identity, in the change of people's behavior, especially of the youth. Post modernity realizes changes of values, and the Media, which has an important role in the idols's construction, profits to sell its' products,. The process goes through various phases: the preparation, the success, and the challenges of the idols.
\end{abstract}


Keywords: Post Modernity, Religion, Idolatry, Ethics, Esthetics, Social Responsibility.

\section{Introdução}

A finalidade desta pesquisa é buscar a influência de pessoas que são transformadas em ídolos pela Mídia, e identificar a importância que estão exercendo na identidade do país, e a influência no comportamento dos jovens.

A religião está no ar! Não a religião das nossas igrejas institucionais, mas, hoje, tudo se torna religião. É um dado antropológico que as pessoas humanas precisam de Deus. Quando não acreditam em Deus, colocam algo ou alguém em seu lugar, para substituí-lo. Várias coisas como fama, dinheiro, poder exercem este papel. Na verdade, existem imagens primordiais, resíduos arcaicos que influenciam a vida, fazendo com que seja o que ela é, e num certo sentido a modelam. E nesse sentido, cada um participa de uma idéia englobante, que vai dar sentido à sua vida. Desta forma, "pode-se criar uma pessoa coletiva, que sirva à condensação do sonho; ou, ainda, reunir numa única imagem de sonho os traços de duas ou mais pessoas" parte crescente da atividade onírica na vida social cria uma "pessoa coletiva", da qual cada indivíduo não é senão um elemento ínfimo. Os sonhos projetados sobre os esportistas, os cantores, os atores, constituem uma participação mágica que nos proporciona felicidade, diante da apresentação dos atores e atrizes de televisão, dos jogadores de football, enfim, a atração exercida por eles e elas criam uma ambiência emocional, cujas vibrações podem ser lidas na superfície das coisas, uma ambiência que encontra sua expressão numa estetização crescente da existência ${ }^{2}$.

Sempre existiram ídolos. Na Bíblia, especialmente nos livros proféticos aparecem os ídolos, os Baals, que eram adorados e colocados no lugar de Yahweh, nos quais o povo acreditava, a quem oravam, e até ofereciam sacrifícios (cf. Oséias, Jeremias, Ezequiel e Isaías).

Mas, nossos ídolos pós-modernos são diferentes. A realidade se encarna nos mitos. Eles nos precedem e ultrapassam. Todo conjunto social encontra um sentido transcendente, mesmo que seja uma transcendência imanente ${ }^{3}$. O divino se encarna no social. Daí, a urgência para compreender o social.

\footnotetext{
${ }^{1}$ S. FREUD, L'interpretation des rêves, Paris, PUF, 1967, p. 264 apud M.. MAFFESOLI, Elogio da razão sensível, Petrópolis, Vozes, 4a. Ed. 2008, p.106

${ }^{2}$ Cf. MAFFESOLI, op. cit. p 106.

${ }^{3}$ Cf. ibidem p.101.
} 
Hoje os ídolos são outros: da música, como Mikael Jackson, Amy Winehouse, Justin Bieber; da televisão, das artes, da política, da moda, dos esportes, principalmente do football.

$\mathrm{Na}$ verdade, o football se tornou uma religião. Tem deuses (os jogadores), rituais, que são celebrados com muitos fiéis, (os torcedores), acontecem em lugares determinados (os campos) e tempo determinados. Enfim, têm todas as características de uma religião: deuses, rituais, lugares, espaços e tempo próprios. A multidão (os fiéis) que vão assistir aos jogos se torna "um nós",(Durkheim), entram em comunhão, transforma-se numa comunidade onde um se funde nos outros que são do mesmo time. Este sentimento de pertença nos faz sentir parte de um conjunto, que ultrapassa cada membro do conjunto. Este lugar os une entre si, fornece uma forma, proporciona uma identidade impõe uma emoção coletiva, que orienta as vontades individuais e assim, faz a sociedade. Os jogos se constituem em sonhos coletivos, que ultrapassam cada indivíduo e o integram num conjunto mais amplo.

O football faz parte do "imaginário" dos brasileiros. Ele define a identidade nacional: Brasil, país do football. Nos jogos, nos estádios, faz-se experiência de uma paixão coletiva, onde acontece uma explosão de alegria ou de dor, de sofrimento, uma competição entre as torcidas, uma forte, muitas vezes, violenta vibração das massas. Os jogadores que chegam ao sucesso, se tornam ídolos da pós-modernidade, os heróis, os mitos, uma "cristalização dos sonhos coletivos"4. Exercem uma fascinação e começam a ser apresentados como modelos para a vida social, estão em congruência com o espírito do tempo, e provocam uma mudança de valores na sociedade ${ }^{5}$. Mobilizam multidões, que querem não somente vê-los jogar, mas também, saber tudo sobre suas vidas, para poder imitá-los, criando afinidades, simpatia, comportamentos. O sonho dos meninos (agora também das meninas), especialmente das classes populares é de tornar-se um jogador. Embora, o football, como esporte nacional atinge todas as classes.

Estas reflexões me foram suscitadas pela urgência de compreender a estruturação social, e ela será realizada em três momentos: que chamarei de Cosmética, Estética e Ética.

\footnotetext{
${ }^{4}$ Cf. idem, Iconologies, nos idolatries post modernes, Paris, Albin Michel, 2008, p. 9

${ }^{5}$ Cf. idem . Elogio da razão sensível, p. .182
} 


\section{Cosmética}

Momento formativo do ídolo, e momento de transformação do seu trabalho em fetiche. Ao ideal racional que foi a marca da Modernidade segue-se a articulação da razão com a emoção, os sentimentos, a imaginação, propícios a criar um ambiente idolátrico nos nossos dias ${ }^{6}$. Emerge com força e vigor e é aproveitada pela "sociedade do espetáculo", esta em que vivemos. O que faz a diferença entre nosso tempo e outros períodos é a espetacularização da imagem, e seu efeito sobre a massa dos cidadãos contemporâneos, transformados em platéia ou em uma multidão de consumidores da subjetividade dos outros ${ }^{7}$. A cultura das sensações consome a imagem dos atores, dos esportistas, dos cantores, dos atores, de religiões e de políticos. Com a espetacularização da imagem perde-se a dimensão humana e singular, aquilo que revela as pessoas, a partir, do ponto de vista, de sua história de vida.

Poderíamos olhar para Ronaldo, o fenômeno, um menino pobre, com um extraordinário talento para o football. Rapidamente, se tornou um ídolo, reconhecido como o "melhor jogador do mundo" por três vezes. De um dia para o outro passou de seu pequeno time para astro da seleção brasileira, um verdadeiro herói nacional. De herói passou a símbolo sexual, de símbolo a fetiche publicitário, de produtos ligados ou não ao football, em conseqüência é transformado em imagem. Não se pode separar sua vida pessoal desta imagem construída, elas se confundem. Quando a Mídia percebe o carisma de uma pessoa, imediatamente, ela transforma esta pessoa em imagem para vender um produto. Eles começam a ter as mesmas propriedades das mercadorias. No caso de Ronaldo foi muito importante o papel da Nike. Não somente vestem a camisa dos produtos, que são pagos para anunciar, mas tornam-se tributários das estratégias de venda destas indústrias. Ganham salários milionários, que não são mais interpretados como resultado dos seus esforços e talento, mas sua celebridade começa a apoiar-se sobre a notícia dos seus salários milionários. Os jovens que os idolatram, começam a sonhar com esta mesma vida, começam a imitá-los, a viver seus valores.

Portanto, nesta primeira fase, a pessoa, como um produto cosmético, é rapidamente transformado, e com seu sucesso se torna um produto. Neste momento, presenciamos isto no novo ídolo que está sendo criado, Neimar. Todos os meninos querem cortar o cabelo igual a ele. E daí, passam do exterior para o tipo de comportamento.

${ }^{6}$ Cf. Idem Elogio da razão sensível, op. cit p. 53.

${ }^{7}$ Cf. P. WATIER, Une introduction à la Sociologie compréhensive, Circé, Birval, 2002, p.13. 


\section{Estética}

Este o segundo momento. Para bem perceber o fenômeno da criação de um ídolo, e de sua vitalidade própria, é necessário um novo olhar. A estética, palavra que vem do grego aisthesis, significa "o que é vivido junto", portanto, aquilo que provoca "um vínculo emocional". A credibilidade surge da ressonância ou dissonância com a experiência pessoal, local, concreta das pessoas.

Por isso, é muito forte o trabalho da Mídia sobre a população. Nosso herói começa a ter uma imagem colada a eles mesmo, a tal ponto que não se sabe mais distinguir quem é a pessoa, quem é o personagem. A sociedade do espetáculo valoriza aqueles que são vitoriosos, que tem talento, carisma. Provindo dos meios populares, com seu sucesso, apontam para uma qualidade de vida, que lhes dá credibilidade, um poder de sedução e um potencial de mobilização de mudança de vida. Os jovens com sua capacidade de entrar em contato com o outro de um modo natural, vibram com seus heróis, o experimentam coletivamente. Esta estética da recepção repousa sobre a intuição, e aos poucos, estes jovens vão mudando seus costumes. Constitui-se um fenômeno complexo, contraditório, que tem influência sobre as decisões de um grande número de pessoas. Os ídolos, os ícones, os mitos nascem das circunstâncias, e nos fazem perceber que o mundo social é o resultado de nossas representações, de nosso imaginário, de nossos desejos e sonhos, que são manipulados pela Mídia.

No entanto, ao contrário da história, que tinha um sentido e uma verdade, a mitologia é uma seqüência de episódios efêmeros. Pode-se dizer que há um claro-escuro onde não se pode ver claramente. Aqueles que chegam ao topo tem a responsabilidade de ser exemplos para os outros que se projetam neles. Tornam-se pessoas públicas, famosos, idolatrados. São os mitos atuais, os ícones da pós-modernidade. Mas, a indústria cultural captura sua imagem e faz a promoção de sua espetacularização e de seu efeito sobre a massa. Ganham muito, porque interessam à Mídia, que constrói suas imagens de acordo com seu interesse financeiro.

Como os ídolos marcam nossa vida e influenciam nossas emoções comuns? O vínculo social está dominado pelo afeto e constituído por um vigoroso sentimento de aparência ${ }^{8}$ e de pertença.

Neste primeiro ponto, a cosmética é a preparação do ídolo, no segundo, a estética é o resultado do trabalho da mídia sobre ele.

\footnotetext{
${ }^{8}$ Cf. idem Elogio da razão sensível p. 137
} 


\section{3. Ética}

A sedução deste sucesso dificilmente se mantém, a credibilidade destas pessoas se fragmenta, o potencial de mobilização se evapora como "plástico degradável", por isso, percebe-se o efêmero, porque este sucesso idolátrico dura pouco. Então começa o terceiro momento. Ao sucesso pode se seguir a decadência, à ascensão pode seguir a queda. Valoriza-se o que provoca mais sensacionalismo, o que causa o máximo impacto, porque no mundo sobrecarregado de informações, somente uma mensagem mais chocante que a precedente consegue atrair as atenções ${ }^{9}$. Acolhem-se as experiências como elas se apresentam. O que é valorizado é o que interessa, neste momento, o que toca as pessoas, quer em particular, quer em grupo.

Mas, estes jovens tornados ídolos não estão preparados para agüentar o peso do sucesso, não tiveram uma formação de valores que os sustentasse neste estilo de vida nova. Eles são vulneráveis e começam a agir de maneira irresponsável, sem refletir sobre seu futuro, sobre a influência que exercem sobre outras pessoas. Poderíamos afirmar até, por parte deles, uma insensibilidade moral. Somente buscam novas sensações, cada vez mais fortes e diferentes, e isso os atinge, e o pior atinge as massas que os imitam.

Hans Jonas fala na Ética da Responsabilidade, mas eles não distinguem o bem do mal que estão produzindo. O resultado final para estes ídolos é a decepção, vidas quebradas, o esquecimento, o tempo vivido em lapsos, cortados do passado e do futuro ${ }^{10}$, fechados sobre si mesmos e independentes entre si. Seu sucesso é efêmero e passageiro. Ocorre uma banalização de suas vidas, com os excessos de toda espécie, sexo, drogas, atividades marginais, que tem como conseqüência uma qualidade inferior de seu trabalho; mas não ligam, não se preocupam, se acham seres especiais e acreditam que podem fazer tudo.

No entanto, começam a aparecer as dificuldades para conservar a imagem fabricada. E com ela a pergunta: como permanecer com esta imagem de sucesso, para que ela continue a vender os produtos e possam ganhar como antes. Surge também por parte dos "fiéis" a decepção, perdem seu "sonho coletivo", ficam fragmentados.

\footnotetext{
${ }^{9}$ Cf. J-F LYOTARD, Noralités postmodernes, Paris, Galiulée, 1993, p.25 apud BAUMAN op. cit p. 59

${ }^{10}$ Cf. Z. BAUMAN, La vie en miettes.Expérience postmoderne et moralité, Paris, Hachette, 2002, p. 45.
} 
Então nos perguntamos, o que é a Ética hoje? Z. Bauman ${ }^{11}$ afirma que na pós-modernidade a ética foi substituída pela "indiferencia-ação", o outro não interessa. A questão é: o que é interessante neste momento? Que ídolos continuam a ser interessantes neste momento? Qual vai ser o comportamento que vai influenciar?

J. Baudrillard afirma que "a Mídia fala até ao esgotamento das tragédias coletivas ou pessoais, até que voltem a se interessar por novas figuras e novos horizontes" ${ }^{\prime 2}$. Isto o que caracteriza nossa época fragmentária e paradoxal.

\section{Conclusão}

Esta reflexão em três momentos buscou apresentar uma estrutura daquilo que está ocorrendo hoje, com nossos heróis pós-modernos, e a influência que eles-elas exercem sobre a sociedade. Eles atravessam três fases: sucesso (cosmética), manipulação midiática e influência afetiva (estética), irresponsabilidade e decepção (Ética). Desta forma, demonstram que o sucesso é efêmero, passageiro. A Estética significando aquilo que é sentido, experimentado junto produz alegria num primeiro momento, mas decepção e frustração, no final. A Ética da Estética, o comportamento vivido junto, que começa com tantas perspectivas de sucesso, de fama, de dinheiro termina em desapontamento e desilusão para aqueles que os idolatravam.

Alguns destes pseudo-herois chegam a superar a decepção causada e ter sucesso depois de uma tragédia: a morte de Mikael Jackson significou isto. Depois de dois anos sem se apresentar, morre quando ia fazer um novo show, e então, volta a ser um ídolo e vende milhões de discos. No caso de Ronaldo, que não estava em forma física adequada e não estava jogando bem, caiu bem a aposentadoria precoce. Logo depois de anunciar sua aposentadoria dos campos, ele voltou à mídia, aparecendo em todos os programas de todos os canais de TV, porque interessava à mídia. Uma verdadeira batalha publicitária para conservar o mito, e para que sua imagem vendesse produtos, até que aparecesse um outro mais interessante que ele. O Neimar já está sendo preparado para isto!

No entanto, o mal que provocaram no imaginário e no comportamento dos jovens, que viam neles e nelas modelos a seguir é incomensurável. Muitos sentem-se perdidos e não sabem mais como agir, já que perderam seus valores

${ }^{11}$ Cf. ibidem p. 58

${ }^{12}$ Cf. J. BAUDRILLARD, Amérique, Paris, Grasset, 1986, p 221-222 apud BAUMANN, op. cit. p.60 
antigos e as cópias que viviam se desfizeram em pó. Isto afeta poderosamente a estrutura da sociedade, sua identidade, seus sonhos coletivos. É importante a conscientização deste processo para poder fazer face a ele e trabalhar para retificar o comportamento.

\section{Referências Bibliográficas}

BAUMAN, Z., La vie en miettes. Expérience postmoderne et moralité, Paris, Hachette. 2003

HANS JONAS, O Princípio da Responsabilidade, Contraponto, 2006

MAFFESOLI, M., Elogio da razão Sensivel, Petrópolis, Vozes, 2008

, Iconologies. Nos idolatries postmodernes, Paris, Albin Michel, 2008

WATIER, P., Une introduction à la Sociologie Compréhensive, Circée, Birval, 2002

Ana Maria Tepedino

Doutora em teologia Sistemática pela PUC-Rio, onde leciona Eclesiologia na Graduação e na Pós-Graduação e pós-doutora em Sociologia na Sorbonne-Paris

Artigo Recebido em 15/08/2011

Artigo Aprovado em 17/11/2011 